\title{
Effects of Glucose on Sorbitol Pathway Activation, Cellular Redox, and Metabolism of myo-Inositol, Phosphoinositide, and Diacylglycerol in Cultured Human Retinal Pigment Epithelial Cells
}

\author{
Thommey P. Thomas, Francesca Porcellati, Koichi Kato, Martin J. Stevens, William R. Sherman, ${ }^{*}$ and Douglas A. Greene \\ Department of Internal Medicine, University of Michigan, Ann Arbor, Michigan 48109; and *Department of Psychiatry, Washington \\ University School of Medicine, St. Louis, Missouri 63310
}

\begin{abstract}
Sorbitol (aldose reductase) pathway flux in diabetes perturbs intracellular metabolism by two putative mechanisms: reciprocal osmoregulatory depletion of other organic osmolytes e.g., myo-inositol, and alterations in NADPH/NADP ${ }^{+}$and/or NADH $/ \mathrm{NAD}^{+}$. The "osmolyte" and "redox" hypotheses predict secondary elevations in CDP-diglyceride, the rate-limiting precursor for phosphatidylinositol synthesis, but through different mechanisms: the "osmolyte" hypothesis via depletion of intracellular myo-inositol ( the cosubstrate for phosphatidylinositolsynthase) and the "redox" hypothesis through enhanced de novo synthesis from triose phosphates. The osmolyte hypothesis predicts diminished phosphoinositide-derived arachidonyldiacylglycerol, while the redox hypothesis predicts increased total diacylglycerol and phosphatidic acid. In high aldose reductase expressing retinal pigment epithelial cells, glucose-induced, aldose reductase inhibitor-sensitive CDP-diglyceride accumulation and inhibition of ${ }^{32} \mathrm{P}$-incorporation into phosphatidylinositol paralleled myo-inositol depletion (but not cytoplasmic redox, that was unaffected by glucose) and depletion of arachidonyl-diacylglycerol. $3 \mathrm{mM}$ pyruvate added to the culture medium left cellular redox unaltered, but stimulated $\mathrm{Na}^{+}$-dependent myo-inositol uptake, accumulation, and incorporation into phosphatidylinositol. These results favor myo-inositol depletion rather than altered redox as the primary cause of glucose-induced aldose reductase-related defects in phospholipid metabolism in cultured retinal pigment epithelial cells. ( $J$. Clin. Invest. 1994. 93:2718-2724.) Key words: Diabetes • diabetic retinopathy $\bullet$ aldose reductase $\bullet$ phosphoinositide $\bullet$ myoinositol.
\end{abstract}

\section{Introduction}

Beneficial effects of aldose reductase (AR2) ${ }^{1}$ inhibitors (ARIs) that block conversion of glucose to sorbitol in animal and human diabetes strongly implicate the sorbitol pathway as a signif-

Address correspondence and reprint requests to Douglas A. Greene, M.D., 3920 Taubman Center Box 0354, University of Michigan Medical Center, 1500 E. Medical Center Dr., Ann Arbor, MI 48109-0354.

Received for publication 8 December 1993 and in revised form 1 February 1994.

1. Abbreviations used in this paper: AR2, aldose reductase; ARI, aldose reductase inhibitor; CDP-DG, CDP-diglyceride; DAG, diacylglycerol; DG, diglyceride; L/P, lactate-to-pyruvate ratio; MI, myo-inositol; PA, phosphatidic acid; PI, phosphatidylinositol; PPI, phosphoinositides; RPE, retinal pigment epithelial; SDH, sorbitol dehydrogenase.

J. Clin. Invest.

(c) The American Society for Clinical Investigation, Inc.

$0021-9738 / 94 / 06 / 2718 / 07 \quad \$ 2.00$

Volume 93, June 1994, 2718-2724 icant factor in the pathogenesis of the long-term complications of diabetes mellitus, particularly diabetic polyneuropathy (1). Two distinct (but not mutually exclusive) biochemical consequences of increased metabolic flux of glucose through the sorbitol pathway have been invoked to explain the short- and long-term deleterious effects of hyperglycemia on tissue function and structure in diabetes. These are the osmoregulatory consequences of sorbitol accumulation (the "osmotic" or "compatible osmolyte" hypothesis) (2-5), and the effects of sorbitol pathway on the NADH/NAD ${ }^{+}$and NADPH/ $\mathrm{NADP}^{+}$redox couples linked, respectively, to AR2 and sorbitol dehydrogenase (SDH) (the "redox" hypothesis) (6-9). A recent revision and expansion of the redox hypothesis specifcally emphasizes the shift in the cytoplasmic NADH/NAD ${ }^{+}$ redox couple by SDH that mimics the metabolic effects of tissue hypoxia ("metabolic pseudohypoxia" hypothesis) (9).

The hallmark of Kinoshita's classical osmotic hypothesis is that cell "swelling," particularly in the ocular lens exposed to hyperglycemia, represents the direct osmotic consequence of intracellular sorbitol accumulation (2). A modern revision of this hypothesis identifies sorbitol as one of a class of nonionic, nonperturbing, compatible intracellular osmolytes that include myo-inositol (MI), taurine, betaine, and glycerophosphorylcholine (4). Under hypertonic stress, these compounds accumulate intracellularly in a carefully balanced and regulated compensatory fashion through the induction of relevant genes such as AR2, the Na-MI cotransporter and others (1012). Under isotonic hyperglycemic stress, sorbitol accumulates by mass action rather than gene induction, with glucose functioning metabolically as an AR2 substrate rather than an osmolyte. Since the other compatible osmolytes are present at basal isotonic rather than hypertonic-stress concentrations, they fall to critically low intracellular levels as sorbitol accumulates, and thus become limiting for their own normal intracellular metabolism. In particular, MI depletion is sufficiently profound to limit the synthesis of phosphatidylinositol (PI) by CDP-diglyceride-inositol 3-phosphatidyltransferase (PI synthase) (13, 14), secondarily altering phosphoinositide (PPI) turnover and the generation of PI-derived second messengers such as diacylglycerols (DAGs) thought to critically regulate $(\mathrm{Na}$, K)-ATPase $(1,15,16)$.

The central assumption of the redox hypothesis is that rapid flux through AR2 and SDH oxidizes the NADPH/ $\mathrm{NADP}^{+}$and reduces the NADH/NAD ${ }^{+}$redox couples, thereby perturbing a range of other adenine nucleotide-linked reactions. In diabetes, oxidation of NADPH $/ \mathrm{NADP}^{+}$may enhance susceptibility to oxidative tissue damage through depletion of reduced glutathione, although supporting evidence has been equivocal ( 7 ). Reduction of NADH/NAD ${ }^{+}$by the oxidation of glucose-derived sorbitol to fructose $(8,9)$ would favor lactate production and divert glycolytic intermediates to the synthesis of phospholipid precursors such as $\alpha$-glycerophos- 
phate, phosphatidic acid (PA), DAG, and CDP-diglyceride (CDP-DG), while at the same time interfering with $\beta$-oxidation of long-chain fatty acids, giving a metabolic profile similar to that of ischemia (9).

Recent studies using a nontransformed cultured human retinal pigment epithelial cell line (RPE 91) with high AR2 gene expression (17) and enzymatic activity (18) have associated glucose-induced, ARI-sensitive depletion of specific intracellular MI pools with an altered pattern of PPI metabolism. The steady state concentration of CDP-DG, the PI-synthase cosubstrate, rose while ${ }^{32} \mathrm{P}$-incorporation into PI declined (13). This was accompanied by a reduction in PPI-derived arachidonylDAG (14). The present study was designed to explore whether CDP-DG accumulation reflected inhibition of PI synthase by MI depletion, as would be predicted by the osmolyte hypothesis, or increased PA and diglyceride (DG) synthesis, as would be predicted by the redox hypothesis (9). Accordingly, the effects of added medium glucose and pyruvate (to oxidize $\mathrm{NADH} / \mathrm{NAD}^{+}$through the lactate dehydrogenase reaction) on the cytoplasmic $\mathrm{NADH} / \mathrm{NAD}^{+}$ratio and the cellular levels of several PPI metabolites were explored in RPE 91 cells with high intrinsic AR2 expression where effects of sorbitol pathway would be most readily discerned.

\section{Methods}

MEM, Hanks' balanced salt solution, and trypsin-EDTA were obtained from Gibco Laboratories (Grand Island, NY); calf serum (CS) from Hyclone Labs (Logan, UT); chemicals and enzymes for lactate and pyruvate measurements, carbachol, D-glucose, Hepes, phosphatidic acid, ATP, diethylenetriaminepentaacetic acid, 4-pyrrolidinopyridine, and benzoic anhydride from Sigma Chemical Co. (St. Louis, MO); cardiolipin from Avanti (Pelham, AL); octyl- $\beta$-glucoside from Boehringer Mannheim (Indianapolis, IN); $\left[\gamma-{ }^{32} \mathrm{P}\right]$ ATP from ICN (Irvine, CA); DAGs from Serdary Research Laboratories (Ontario, Canada); HPLC columns from either Rainin (Emeryville, CA) or Supelco (Bellefonte, PA); and TLC plates from Merck (Rahway, NJ). All the solvents for chromatography were HPLC grade. Tissue culture supplies were from Corning Glass Works (Corning, NY) and Costar (Cambridge, MA). Baker Chemical Co. (Phillipsburg, NJ) and Fisher Scientific (Fair Lawn, NJ) supplied other reagent grade chemicals.

\section{Cell culture}

The Michigan Eye Bank supplied human postmortem eyes from which primary RPE cell lines were established by a modification (19) of the method of Delmonte and Maumenee (20). Briefly, the RPE cells were gently vacuumed from Bruch's membrane after removal of the anterior segment, vitreous, and neurosensory retina. Aspirated cells were evenly plated into sterile uncoated $35-\mathrm{mm}$ culture dishes, and colony formation was monitored by phase-contrast microscopy. Confluent cells were subcultured at a density of $3-5 \times 10^{6}$ cells per $75 \mathrm{~cm}^{2}$ tissue culture flask in MEM containing $2 \mathrm{mM}$ glutamine and $5 \mathrm{mM}$ glucose with $20 \%$ CS. Cells were detached in $0.05 \%$ trypsin and $0.53 \mathrm{mM}$ EDTA for $10 \mathrm{~min}$ at $37^{\circ} \mathrm{C}$. After addition of MEM with $20 \% \mathrm{CS}$, cells were centrifuged for $5 \mathrm{~min}$ at $430 \mathrm{~g}$ and resuspended in media. Cells were maintained at $37^{\circ} \mathrm{C}$ in humidified $95 \% \mathrm{O}_{2} / 5 \% \mathrm{CO}_{2}$ with fresh media changed every other day. Experiments were performed on passage numbers 10-19 of RPE 91 cells that exhibit rapid and profound sorbitol accumulation and glucose-induced MI depletion in association with high level AR2 gene expression and activity, and are thus described as a "high AR2" RPE cell line $(17,19)$.

\section{Biochemical measurements}

Polyol pathway intermediates. Cellular glucose, sorbitol, fructose, and MI were measured as trimethylsilyl derivatives by capillary gas chromatography with a flame ionization detector (19). Cells were washed with
$3 \mathrm{ml}$ of serum-free MEM containing $3.5 \mathrm{mg} / \mathrm{ml}$ bovine serum albumin, lysed in $1 \mathrm{ml}$ water for $15 \mathrm{~min}$ at $37^{\circ} \mathrm{C}$, and scraped. The lysate from each well plus a corresponding 1-ml rinse of water was sonicated, deproteinized with $5 \% \mathrm{ZnSO}_{4}$ and $0.3 \mathrm{~N} \mathrm{Ba}(\mathrm{OH})_{2}$, and centrifuged. 1 $\mathrm{ml}$ of clear supernatant was combined with $5 \mu \mathrm{g} \alpha$-methyl D-mannoside as an internal standard, lyophilized, and derivatized with a 10:2:1 ( $\mathrm{vol} / \mathrm{vol}$ ) mixture of dried pyridine, hexamethyldisilazane, and trimethylchlorosilane (Pierce Chemicals Co., Rockford, IL). The trimethylsilyl derivatives were dried and solubilized in hexane. $1 \mu \mathrm{l}$ of the sample was injected into a gas-liquid chromatograph (model 3400; Varian, Walnut Creek, CA), fitted with a flame ionization detector and a 30-m Megabore column (model DB-1; J \& W Scientific, Folsom, CA) containing $100 \%$ polysiloxane with $\mathrm{He}$ as a carrier gas. The initial column temperature of $160^{\circ} \mathrm{C}$ was held for $1 \mathrm{~min}$ and was programmed to rise $50^{\circ} \mathrm{C} / \mathrm{min}$ to $210^{\circ} \mathrm{C}$, which was held for the duration of the run. Area counts were digitized by a data system (model 402; Varian) and corrected for the internal standard. A standard curve was generated each day for MI, sorbitol, fructose, and $\alpha$-methyl D-mannoside, and recovery of added metabolites to RPE samples was consistently $>95 \%$ (19).

MI uptake and synthesis. $\mathrm{Na}^{+}$-dependent MI uptake, was determined (19) in cells rinsed with the following (mM): 10 Hepes, 128

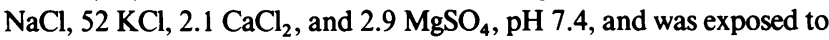
$1-500 \mu \mathrm{M}$ of $\left[2{ }^{3} \mathrm{H}\right] \mathrm{MI}$ for $5 \mathrm{~min}$ before lysis in water and sonication. Aliquots of sonicate were assessed for $\left[{ }^{3} \mathrm{H}\right] \mathrm{MI}$ by liquid scintillation spectrometry. Synthesis of MI was determined by incubating cells in medium containing 5 and $20 \mathrm{mM} \mathrm{6,6-dideuteroglucose} \mathrm{in} \mathrm{place} \mathrm{of}$ glucose for $1 \mathrm{wk}$, after which cells were rinsed with PBS and precipitated with trichloroacetic acid. The degree of MI synthesis was assessed by measuring the incorporation of deuterium from 6,6-dideuteroglucose (MSD Isotopes, Montreal, CA ) into MI using gas chromatography mass spectrometry. Aliquots of the sonicate were taken to dryness and the inositols converted to the butane boronic esters by shaking overnight with butane boronic acid ( $10 \mathrm{mg}$; Sigma Chemical Co., Milwaukee, WI) in pyridine ( $1 \mathrm{ml})(21)$. A Hewlett-Packard (model 5970; Palo Alto, CA ) system was used, with electron impact ionization in the analysis. The separation was carried out on a fused silica column (model DB-17, $15 \mathrm{~m} \times 0.25 \mathrm{~mm}$ i.d., $0.25 \mu \mathrm{m}$ film; J \& W Scientific). The degree of labeling of newly synthesized MI was assessed using ion monitoring of $\mathrm{m} / z 321$ for unlabeled MI and $\mathrm{m} / z 322$ for the labeled MI (only one deuterium from the 6,6-dideuteroglucose is incorporated in MI synthesis) (22).

Lactate and pyruvate. The lactate/pyruvate $(\mathrm{L} / \mathrm{P})$ ratio was measured spectrofluorimetrically (23) as an index of cytoplasmic NADH/ $\mathrm{NAD}^{+}$. Cells were rinsed with ice-cold PBS and extracted with $0.6 \mathrm{M}$ perchloric acid. The supernatant from the perchloric acid extract was neutralized with potassium carbonate, concentrated by freeze drying and stored at $-80^{\circ} \mathrm{C}$, and assayed for pyruvate and lactate within $1 \mathrm{wk}$. Pyruvate was assayed spectrofluorimetrically with rabbit muscle lactate dehydrogenase at $\mathrm{pH} 7.0$, using alkali fluorescence enhancement (23). Lactate was assayed by direct enzymatic fluorimetric assay with rabbit muscle lactate dehydrogenase and porcine heart glutamate pyruvate transaminase, at $\mathrm{pH} 9.9$.

$P A$ and PI. Cells were prelabeled overnight with $\left[{ }^{32} \mathrm{P}\right]$ orthophosphate $(2 \mu \mathrm{Ci} / \mathrm{ml}, 9 \mathrm{Ci} / \mathrm{mol})$ in $10-\mathrm{cm}$ dishes and extracted and subjected to TLC on $20 \times 20 \mathrm{~cm}$ silica gel- 60 plates developed with chloroform/acetone/methanol/acetic acid (40:15:13:12.8) to yield discrete PA and PI bands $\left(R_{F}=0.75\right.$ and 0.39 , respectively, by comparison with authentic standards), which were scraped and quantitated by liquid scintillation spectrometry. Values were normalized to total phospholipid phosphorus determined colorimetrically after conversion to inorganic phosphate by digestion with perchloric acid at $135^{\circ} \mathrm{C}(13)$.

$C D P-D G$. CDP-DG was quantitated in cells grown in 10-cm dishes after labeling with $\left[5-{ }^{3} \mathrm{H}\right]$ cytidine $(2 \mu \mathrm{Ci} / \mathrm{ml}, 26 \mu \mathrm{Ci} / \mathrm{nmol})$ for $6 \mathrm{~h}$ (13). A discrete CDP-DG band $\left(R_{F}=0.28\right)$ was resolved by TLC as described above, scraped, counted using liquid scintillation spectrometry, and normalized to total phospholipid phosphorus (13).

$D G$. Cellular lipids were extracted and solubilized in $7.5 \%$ octyl- $\beta$ D-glucoside plus $5 \mathrm{mM}$ cardiolipin in $1 \mathrm{mM}$ diethylenetriaminepenta- 
Table I. Effect of Glucose and $3 \mathrm{mM}$ Pyruvate on Sorbitol Pathway Intermediates and Lactate/Pyruvate (L/P) Ratio

\begin{tabular}{lccccc}
\hline \multicolumn{1}{c}{ Conditions } & Sorbitol & Fructose & Lactate & Pyruvate & L/P Ratio \\
& & \multicolumn{2}{c}{ nmol/mg protein } & & \\
& & & & & \\
& ND & $9.7 \pm 1.0$ & $68 \pm 12$ & $0.500 \pm 0.047$ & $134 \pm 16$ \\
$5 \mathrm{mM}$ Glucose & ND & $4.8 \pm 0.6$ & $98 \pm 9^{*}$ & $0.870 \pm 0.095^{*}$ & $111 \pm 15$ \\
$20 \mathrm{mM}$ Glucose + pyruvate & $30.8 \pm 2.7$ & $54.8 \pm 5.5^{*}$ & $54 \pm 8$ & $0.500 \pm 0.017$ & $114 \pm 11$ \\
$20 \mathrm{mM}$ Glucose + pyruvate & $27.1 \pm 3.6$ & $24.3 \pm 2.4^{* \pm}$ & $61 \pm 12$ & $0.815 \pm 0.114^{*}$ & $91 \pm 35$ \\
\hline
\end{tabular}

Cells were exposed for $1 \mathrm{wk}$ to 5 or $20 \mathrm{mM}$ glucose in the presence or absence of $3 \mathrm{mM}$ pyruvate. At the end of incubations, cellular lactate, pyruvate, and the lactate/pyruvate $(\mathrm{L} / \mathrm{P})$ ratio were determined spectrofluorimetrically. The values represent mean $\pm \mathrm{SE}$ of 4 experiments. ${ }^{*} P<0.05$ vs. $5 \mathrm{mM}$ glucose. ${ }^{\ddagger} P<0.05$ vs. $20 \mathrm{mM}$ glucose. $N D$, not detectable.

acetic acid (24). The solubilized DGs $(20 \mu \mathrm{l})$ were phosphorylated to $\left.{ }^{32} \mathrm{P}\right] \mathrm{PA}$ in $100 \mu \mathrm{l} 50 \mathrm{mM}$ imidazole $\mathrm{HCl}(\mathrm{pH} 6.6), 50 \mathrm{mM} \mathrm{NaCl}, 12.5$ $\mathrm{mM} \mathrm{MgCl} 2$, 1 mM EGTA, $2 \mathrm{mM}$ dithiothrietol, $50 \mu \mathrm{g} / \mathrm{ml}$ DG-kinase, and $1 \mathrm{mM}\left[\gamma^{32} \mathrm{P}\right]$ ATP $\left(2.5 \times 10^{5} \mathrm{cpm} / \mathrm{nmol}\right)$. After incubation at $25^{\circ} \mathrm{C}$ for $30 \mathrm{~min}$, the lipids were extracted and subjected to TLC. Radioactivity in the PA band was measured by liquid scintillation spectrometry, and the amount of DG was determined from a curve obtained for DG standards run under identical conditions.

$D A G$ and DAG molecular species. DAGs were isolated and purified, and fatty acid composition determined by HPLC analysis (25). The lipids extracted from the cells were purified by TLC using toluene/ ether/methanol (80:10:10) as the developing solvent. The DG band $\left(R_{F}=0.57\right)$ was identified by comparison with authentic DAGs after spraying with primuline $(0.001 \%)$ and viewing under ultraviolet light. The DG band was scraped, extracted with dry diethylether, dried, and benzoylated using 4-pyrrolidinopyridine as the catalyst. The benzoylated DAGs were separated from alk-1-enylacyl and alkylacylglycerols by a second TLC using hexane/diethylether/7.4 M ammonium hydroxide (55:45:1, vol/vol) as the solvent. The band corresponding to benzoylated DAG standards was identified $\left(R_{f}=0.55\right)$ and extracted with dry diethylether, and purified by normal phase HPLC on a silica gel column, using cyclohexane/ether $(96.3: 3.7 \mathrm{vol} / \mathrm{vol})$ as the mobile

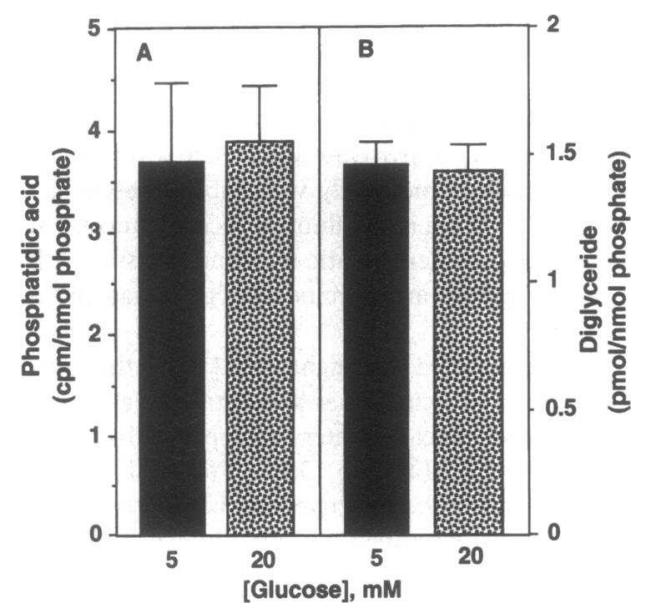

Figure 1. Effect of glucose on PA levels $(A)$ and DG mass $(B)$. RPE cells were exposed for $1 \mathrm{wk}$ to 5 or $20 \mathrm{mM}$ glucose. Cells were labeled with $\left[{ }^{32} \mathrm{P}\right]$ orthophosphate overnight, extracted, and $\left[{ }^{32} \mathrm{P}\right] \mathrm{PA}$ was identified by TLC. For determination of DG mass, the lipids were extracted and DG was enzymatically converted to $\left[{ }^{32} \mathrm{P}\right] \mathrm{PA}$, and identified by TLC. The [ $\left.{ }^{32} \mathrm{P}\right] \mathrm{PA}$ bands obtained were quantitated by liquid scintillation spectrometry. The values represent mean $\pm \mathrm{SE}$ of either $3(A)$ or $4(B)$ independent experiments. phase. The molecular species of DAGs in the purified sample thus obtained were separated by reversed-phase HPLC in an octadecyl silica gel reversed-phase column using acetonitrile/iso-propanol (70:30, vol/ vol) as the mobile phase. The peaks were identified by absorbency at $228 \mathrm{~nm}$ by comparison with a mixture of seven authentic DAGs, and by comparison to previously reported retention times (25). Peak areas were integrated and converted to picmoles per milligram protein using 1,2-distearoyl-sn-glycerol as the internal standard, in a computer attached to the HPLC (Maxima; Waters, Milford, MA).

\section{Statistics}

Values are shown as mean \pm SEM. Unless otherwise stated, statistical significance of differences among groups was analyzed by ANOVA and confirmed post-hoc by Student-Newman-Keuls test, with significance defined at the 0.05 level.

\section{Results}

Effect of $3 \mathrm{mM}$ pyruvate and $20 \mathrm{mM}$ glucose on sorbitol, fructose, and $L / P$ ratio

Incubation of RPE 91 for $1 \mathrm{wk}$ failed to produce detectable alterations in cellular lactate, pyruvate, or the $\mathrm{L} / \mathrm{P}$ ratio (a surrogate for cytoplasmic NADH/NAD $\left.{ }^{+}\right)(8,9)$, despite significant sorbitol and fructose accumulation (Table I). Furthermore, the addition of exogenous pyruvate to the medium also failed to shift cytoplasmic redox (Table I) even though the addition of $3 \mathrm{mM}$ pyruvate to the culture medium raised the medium pyruvate concentration for the entire duration of the experiment, ${ }^{2}$ and attenuated slightly the glucose-mediated rise in fructose (but not sorbitol). Medium pyruvate supplementation did produce a modest increase in cellular lactate in the presence of $5 \mathrm{mM}$ glucose, and in cellular pyruvate in the presence of both 5 and $20 \mathrm{mM}$ glucose, but the $\mathrm{L} / \mathrm{P}$ ratio was not significantly affected by pyruvate in either 5 or $20 \mathrm{mM}$ glucose.

2. The pyruvate content in the media at the conclusion of the $60-65 \mathrm{~h}$ incubation decreased from the initial $3 \mathrm{mM}$ level to $0.84 \pm 0.01$ and $0.89 \pm 0.08 \mathrm{mM}$, respectively, in 5 or $20 \mathrm{mM}$ glucose. In one experiment the time course of this decline in measured medium pyruvate was 2.88 , $2.72,2.66,1.92,1.90$, and $1.11 \mathrm{mM}$ at $0,2,8,24,48$, and $70 \mathrm{~h}$, respectively. In another experiment, in which the medium was changed $6 \mathrm{~h}$ before the cell extraction, the $L / P$ ratio in cells incubated with $20 \mathrm{mM}$ glucose plus $3 \mathrm{mM}$ pyruvate was 104 versus $112 \mathrm{nmol} / \mathrm{mg}$ protein in cells incubated in the presence of $20 \mathrm{mM}$ glucose without added pyruvate, confirming that the lack of an effect of pyruvate on the cellular redox could not be attributed to media pyruvate depletion. 


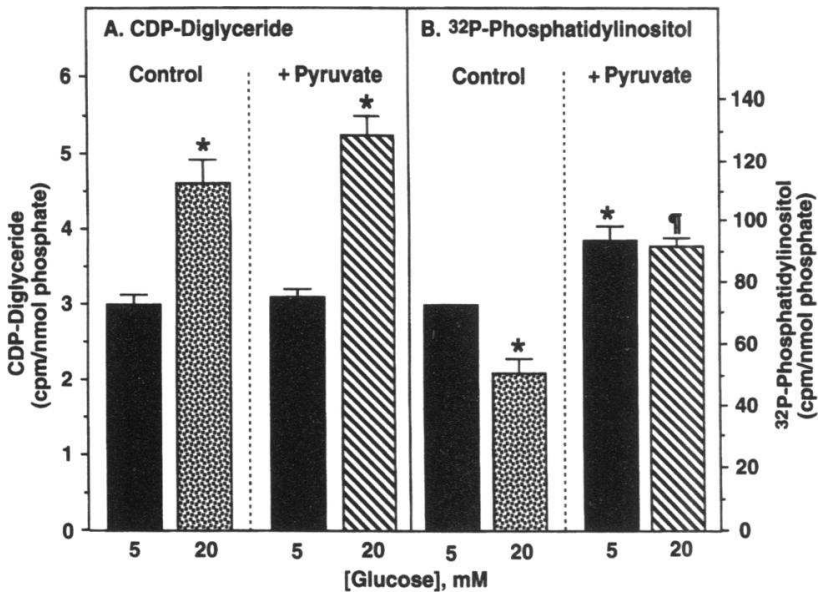

Figure 2. Effect of glucose and pyruvate on CDP-DG levels $(A)$ and ${ }^{32} \mathrm{P}$ incorporation into PI $(B)$. Cells were incubated with 5 or $20 \mathrm{mM}$ glucose in the absence or presence of $3 \mathrm{mM}$ pyruvate for $1 \mathrm{wk}$. Cells were changed to fresh media, exposed to $\left[{ }^{3} \mathrm{H}\right]$ cytidine for $6 \mathrm{~h}(A)$, or $\left[{ }^{32} \mathrm{P}\right]$ orthophosphate overnight $(B)$, and extracted. CDP-DG and [ $\left.{ }^{32} \mathrm{P}\right] \mathrm{PI}$ was quantitated by liquid scintillation spectrometry as described in Methods. The values represent mean $\pm S E$ of 3 experiments. ${ }^{*} P<0.05$ compared with respective controls in the presence of 5 $\mathrm{mM}$ glucose; $P<0.05$ vs. cells in $20 \mathrm{mM}$ glucose.

Thus RPE 91 is capable of buffering the putative redox effects of either $3 \mathrm{mM}$ pyruvate or $20 \mathrm{mM}$ glucose.

\section{Effect of $3 \mathrm{mM}$ pyruvate and $20 \mathrm{mM}$ glucose on DAG metabolism}

$20 \mathrm{mM}$ glucose also failed to induce accumulation of DAG or its metabolic precursors. Neither ${ }^{32}$ P-incorporation into PA nor DG mass were increased after 1-wk exposure of the cells to $20 \mathrm{mM}$ glucose (Fig. 1), and the accumulation of CDP-DG induced by $20 \mathrm{mM}$ glucose (13) was unaffected by pyruvate (Fig. $2 A$ ). Although total DG mass was unaffected by $20 \mathrm{mM}$ glucose (Fig. 1), glucose decreased total DAG modestly, with an exaggerated decrease in the quantities of several PI-associated DAG species (Table II) including arachidonyl-stearoylDAG (14).

\section{Effect of $3 \mathrm{mM}$ pyruvate and $20 \mathrm{mM}$ glucose on \\ ${ }^{32} P$-incorporation into PI, and on MI content, synthesis, and uptake}

Although pyruvate failed to diminish glucose-induced CDPDG accumulation, a marker of PI synthase inhibition in RPE 91 (13), it significantly increased ${ }^{32} \mathrm{P}$-incorporation into PI in both 5 and $20 \mathrm{mM}$ glucose (Fig. $2 \mathrm{~B}$ ). The more robust effect of $3 \mathrm{mM}$ pyruvate in $20 \mathrm{mM}$ glucose eliminated the difference in ${ }^{32} \mathrm{P}$-incorporation in $20 \mathrm{mM}$ versus $5 \mathrm{mM}$ glucose (Fig. $2 \mathrm{~B}$ ). To further characterize and quantitate this phenomenon, the effect of pyruvate on MI content, MI synthesis, and MI uptake in RPE 91 in 5 and $20 \mathrm{mM}$ glucose was assessed. Pyruvate partially, but not completely, corrected the MI depletion induced by $20 \mathrm{mM}$ glucose in RPE 91 (Fig. $3 \mathrm{~A}$ ), thus providing a potential explanation for its stimulation of ${ }^{32} \mathrm{P}$-incorporation into PI.

Since $\mathrm{NAD}^{+}$is an obligate cofactor in the rate-limiting step for MI synthesis from glucose-6-phosphate (22), the effect of pyruvate on MI content might reflect subtle and undetectable shifts in the NADH/NAD ${ }^{+}$redox couple that augmented MI synthesis. De novo MI synthesis, measured as the incorporation of deuterated glucose into MI in RPE 91 cultured for $1 \mathrm{wk}$ in 5 or $20 \mathrm{mM}$ glucose with or without $3 \mathrm{mM}$ pyruvate, was not detected. Incorporation of deuterium from 6,6-dideuteroglu-

Table II. Effect of $20 \mathrm{mM}$ Glucose on DAG Molecular Species in RPE 91 Cells

\begin{tabular}{lllll}
\hline \multicolumn{1}{c}{ Peak } & \multicolumn{1}{c}{ DAG species } & $5 \mathrm{mM} \mathrm{Glu}$ & $20 \mathrm{mM}$ Glu & Mean \pm SE \\
\hline & & & & pmol/mg protein \\
1 & $16: 0-22: 6,18: 1-22: 0$ & $1.81 \pm 1.22$ & $3.47 \pm 1.68$ & $+1.66 \pm 0.90$ \\
2 & $18: 1-22: 5,16: 1-16: 1$ & $0.86 \pm 0.63$ & $1.19 \pm 0.51$ & $+0.34 \pm 0.41$ \\
3 & $18: 1-20: 4,16: 0-22: 5$ & $1.78 \pm 1.05$ & $1.66 \pm 0.73$ & $-0.13 \pm 0.61$ \\
4 & $16: 0-20: 4$ & $3.45 \pm 1.46$ & $2.43 \pm 0.80$ & $-1.03 \pm 1.03$ \\
5 & $16: 1-18: 1,18: 1-18: 2,18: 1-22: 4,18: 1-20: 3$ & $10.0 \pm 2.8$ & $8.2 \pm 2.5$ & $-1.8 \pm 0.7^{*}$ \\
6 & $16: 0-16: 1,16: 0-18: 2,16: 0-22: 5,16: 0-20: 3$ & $23.4 \pm 4.2$ & $17.5 \pm 3.2$ & $-5.9 \pm 1.7^{*}$ \\
7 & $18: 0-22: 5$ & $7.81 \pm 0.87$ & $5.56 \pm 0.55$ & $-2.24 \pm 0.74^{*}$ \\
8 & $18: 0-20: 4,16: 0-20: 3$ & $8.77 \pm 2.84$ & $6.86 \pm 2.63$ & $-1.91 \pm 0.73^{*}$ \\
9 & $18: 1-18: 1$ & $14.2 \pm 3.5$ & $12.1 \pm 3.4$ & $-2.1 \pm 0.9^{*}$ \\
10 & $16: 0-18: 1,18: 0-18: 2,18: 0-22: 4,18: 0-20: 3$ & $61.2 \pm 10.7$ & $49.5 \pm 8.5$ & $-11.7 \pm 2.9^{*}$ \\
11 & $16: 0-16: 0$ & $44.7 \pm 4.7$ & $34.4 \pm 3.2$ & $-10.3 \pm 3.1^{*}$ \\
12 & $17: 0-18: 1$ & $2.54 \pm 0.61$ & $2.10 \pm 0.52$ & $-0.44 \pm 0.72$ \\
13 & $18: 1-20: 1$ & $3.34 \pm 0.54$ & $2.57 \pm 0.53$ & $-0.77 \pm 0.50$ \\
14 & $18: 0-18: 1,16: 0-20: 1$ & $18.1 \pm 3.0$ & $18.7 \pm 3.3$ & $+0.6 \pm 2.2$ \\
15 & $16: 0-18: 0$ & $26.9 \pm 2.2$ & $27.4 \pm 1.5$ & $+0.5 \pm 1.9$ \\
Total DAG & & $228 \pm 30$ & $192 \pm 24$ & $-36 \pm 8^{*}$ \\
\hline
\end{tabular}

Cells were exposed to 5 or $20 \mathrm{mM}$ glucose (Glu) for $1 \mathrm{wk}$, and the DAG molecular species quantitated as described in Methods. The values given are mean \pm SE from 10 independent experiments. The level of significance of the absolute difference in DAG content between the 5 and $20 \mathrm{mM}$ glucose for each DAG species by paired two-tailed $t$ test confirmed the primary analysis by ANOVA plus Student-Newman-Keuls test based on percentile reductions in individual DAG species. Undetectable peaks were obtained in several experiments for peaks 1,2 and 3 . ${ }^{*} P \leq 0.05$. 


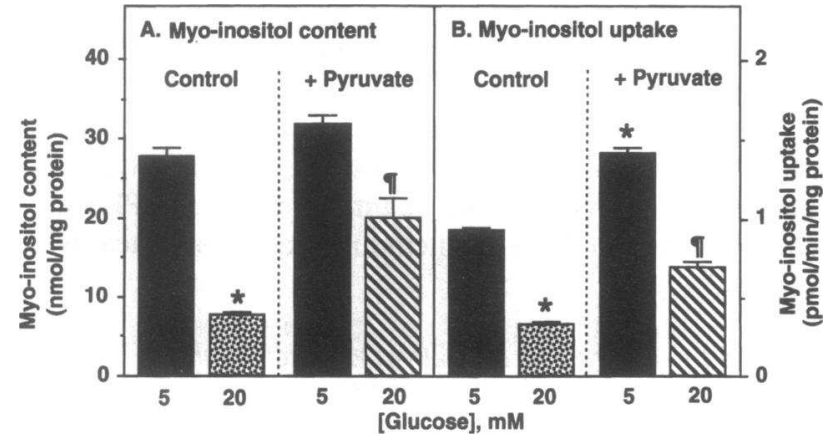

Figure 3. Effect of glucose and pyruvate on MI content $(A)$ and uptake $(B)$. Cells were incubated with 5 or $20 \mathrm{mM}$ glucose in the absence or presence of $3 \mathrm{mM}$ pyruvate. MI content was determined by GLC, and $\mathrm{Na}^{+}$-dependent $\left[{ }^{3} \mathrm{H}\right] \mathrm{MI}$ uptake was determined with a MI concentration in the uptake buffer of $1 \mu \mathrm{M}$, as described in Methods. The values represent mean $\pm \mathrm{SE}$ of 3 observations. ${ }^{*} P<0.05$ vs. respective controls in $5 \mathrm{mM}$ glucose; $P<0.05$ vs. cells in $20 \mathrm{mM}$ glucose.

cose via synthesis would result in an increase, relative to unlabeled MI, in the ratio of the intensity of $\mathrm{m} / \mathrm{z} 322$ to that of $\mathrm{m} / \mathrm{z}$ 321. No significant change in these ratios was observed: unlabeled MI 0.158 (average of three analyses); samples incubated with dideuteroglucose: $0.158,0.160,0.158$, and 0.150 (averages of two analyses per incubation ).

In contrast, the presence of $3 \mathrm{mM}$ pyruvate in the cell culture medium for 1 wk significantly increased the $\mathrm{Na}^{+}$-dependent uptake of $1 \mu \mathrm{M}\left[{ }^{3} \mathrm{H}\right] \mathrm{MI}$ by the high-affinity transport system (19) in the presence of 5 or $20 \mathrm{mM}$ glucose (Fig. $3 \mathrm{~B}$ ). Pyruvate in the culture medium for $1 \mathrm{wk}$ failed to increase $\mathrm{Na}^{+}$-dependent MI uptake at MI concentrations of 10,50 , and $500 \mu \mathrm{M}$ MI, which would primarily reflect the low-affinity uptake system (19): uptake was $33.9 \pm 1.3,54.3 \pm 0.9$, and $67.8 \pm 7.3 \mathrm{pmol} / \mathrm{mg}$ protein per minute at 10,50 , and $500 \mu \mathrm{M}$ $\mathrm{MI}$, respectively, in the absence of pyruvate, and $35.5 \pm 1.9$, $58.8 \pm 3.1$, and $60.2 \pm 4.7 \mathrm{pmol} / \mathrm{mg}$ protein per minute, respectively, in the presence of $3 \mathrm{mM}$ pyruvate. The acute addition of $3 \mathrm{mM}$ pyruvate had no effect on MI uptake at any MI concentration: in a representative experiment at $1.0 \mu \mathrm{M}$ MI that was repeated twice, $\mathrm{MI}$ uptake for cells grown in $5 \mathrm{mM}$ glucose was $1.05 \pm 0.12 \mathrm{pmol} / \mathrm{mg}$ protein per minute in the absence of pyruvate and $1.30 \pm 0.12 \mathrm{pmol} / \mathrm{mg}$ protein per min in the presence of $3 \mathrm{mM}$ pyruvate in the uptake buffer.

\section{Discussion}

These studies specifically addressed the postulate that glucoseinduced, AR2-dependent, SDH-mediated alterations in $\mathrm{NADH} / \mathrm{NAD}^{+}(8,9)$ might underlie the abnormalities in PPI metabolism induced by $20 \mathrm{mM}$ glucose in high AR2-expressing $(17,18)$ cultured RPE 91 cells $(13,14)$. These glucose-induced perturbations in PPI metabolism in RPE $91(13,14)$ are of particular interest because they resemble those induced by diabetes in rat peripheral nerve $(26,27)$ : when peripheral nerve tissue from diabetic rats is incubated in vitro, stimulation of PPI turnover results in abnormal CDP-DG accumulation and diminished release of arachidonoyl-containing DAG (26, 27). The RPE 91 cell model also was chosen because AR2-dependent phenomena in general, and those specifically ascribed to putative secondary perturbations in cytoplasmic redox $(8$,
9), ought to be more readily apparent in cells constitutively overexpressing AR2 $(17,18)$. However, overall fuel and energy metabolism in cultured cells may be qualitatively different from those of perfused tissues in vivo. With this last caveat in mind, the effect of $20 \mathrm{mM}$ glucose $(13,14)$ and $3 \mathrm{mM}$ pyruvate $(8,9,28)$ on AR2 pathway activity; L/P ratio; CDP-DG accumulation; ${ }^{32} \mathrm{P}$-incorporation into PA and PI; total DG content; total content and molecular composition of DAG; and MI content, synthesis, and uptake were studied in RPE 91 cells.

The previously reported (13) accumulation of CDP-DG induced by $20 \mathrm{mM}$ glucose in RPE 91 cells was confirmed. It was unassociated with detectable shifts in $\mathrm{L} / \mathrm{P}$ ratio, a recognized surrogate of NADH/NAD ${ }^{+}(8)$, suggesting that glucoseinduced AR2-dependent CDP-DG accumulation in RPE 91 (13) is unrelated to significant shifts in cytoplasmic redox. Since pyruvate failed to prevent this glucose-induced rise in CDP-DG, it is unlikely that small or transient shifts in NADH/ $\mathrm{NAD}^{+}$might have eluded the $\mathrm{L} / \mathrm{P}$ measurements but still significantly promoted de novo synthesis of CDP-DG via PA and DAG $(8,9)$. (Pyruvate supplementation has been reported to reverse the modest [13\%] glucose-induced increase in $L / P$ ratio and accompanying vascular dysfunction in a skin chamber model for diabetic microvascular complications [28].)

The absence of detectable increases in ${ }^{32} \mathrm{P}$-incorporation into PA or in DAG content in glucose-exposed RPE 91 cells further suggests that increased de novo synthesis is not the major factor underlying glucose-induced CDP-DG accumulation in RPE 91. The previously reported amelioration of glucose-induced CDP-DG accumulation in RPE 91 by increased medium MI (13), although consistent with the osmolyte MI depletion hypothesis ( 18), does not entirely exclude de novo synthesis as a factor in glucose-induced CDP-DG accumulation: MI supplementation could have facilitated metabolic disposition of newly synthesized excess CDP-DG $(8,9)$. However, the marginal fall in total DAG with accentuation in molecular species of PPI origin induced by $20 \mathrm{mM}$ glucose implicates reduced synthesis and turnover of PPI consequent to MI depletion $(13,14,29)$ rather than increased de novo synthesis of $\operatorname{DAG}(8,9)$. The fact that glucose exposure produces a rise in total DAG without MI depletion or CDP-DG accumulation in RPE cells with low AR2 gene expression and enzymatic activity (14) suggests that when glucose-induced stimulation of de novo DAG synthesis (30) occurs, it largely reflects AR2-independent processes. It is tempting to speculate that neither of the major glucose-induced perturbations in phospholipid signal transduction commonly observed in vitro, namely inhibition of PPI turnover (29) and increased de novo synthesis of DAG (30), are primarily mediated by changes in cytoplasmic redox related to AR2 or SDH.

On the other hand, one of the most compelling arguments favoring the redox or metabolic pseudohypoxia hypothesis is the ability of pyruvate to reverse alterations in cytoplasmic redox and vascular dysfunction induced by glucose in granulation tissue (28). Although the addition of pyruvate to RPE 91 did not influence the $L / P$ ratio or CDP-DG, it partially reversed MI depletion induced by glucose, apparently through stimulation of the high-affinity component of $\mathrm{Na}^{+}$-dependent MI uptake (19). It also blunted the glucose-induced rise in fructose but not in sorbitol. Partial MI repletion by pyruvate was sufficient to correct the glucose-induced reduction in ${ }^{32} \mathrm{P}$ incorporation into PI, but not the associated accumulation of CDP-DG, which is a more sensitive indicator of PI synthase 
inhibition by MI depletion ( 13). Whether increased high-affinity $\mathrm{Na}^{+}$-dependent MI uptake (19) induced in RPE 91 by pyruvate reflects enhanced expression or posttranslational modification of Na-MI-cotransporter(s) remains to be established. In either case it suggests a novel unanticipated metabolic regulation of $\mathrm{Na}^{+}$-dependent $\mathrm{MI}$ transport in these cells. The report that MI supplementation mimics some of the reported effects of pyruvate on diabetes- and glucose-induced vascular dysfunction (31) should be reexamined in light of this finding.

Extrapolation of these in vitro data to intact perfused tissues in vivo requires great caution, however. Cultured cells primarily metabolize glucose anaerobically rather than oxidatively so that their lactate and pyruvate metabolism may be qualitatively different from that of most intact perfused tissues in vivo (32). However, the $L / P$ ratio observed in cultured $R P E$ 91 is similar to that observed in incubated erythrocytes, where $50 \mathrm{mM}$ glucose did indeed raise the L/P ratio further (33). Similarly, tissues incubated in vitro or in artificial chambers, if damaged or inadequately oxygenated, may also exhibit artifactually high rates of aerobic glycolysis and lactate accumulation and may be unable to buffer cytoplasmic redox by oxidative metabolism. Thus reproducible meticulously controlled and conducted studies of nonischemic, freeze-clamped complications-prone tissue from diabetic animals will be needed to fully interpret the relevance of changes in $\mathrm{L} / \mathrm{P}$ ratios or DAG content and molecular species to diabetes-induced metabolic tissue damage.

On the other hand, the putative effects of pyruvate on MI transport constitute a novel potential link between sorbitol pathway activation and MI metabolism beyond the classical compatible osmolyte concept of Burg (4). Recent studies in diabetic rats suggest that diabetic peripheral nerve may be ischemic and hypoxic (34) and that inhibition of the sorbitol pathway, which corrects nerve conduction and nerve MI content, may also improve nerve perfusion (35), possibly through a nitric oxide-related mechanism (36). If sorbitol pathway activation contributed to nerve ischemia, which in turn transformed tissue pyruvate to lactate, then a component of ARIsensitive nerve MI depletion in diabetes could reflect true ischemia rather than a compatible osmolyte relationship. This possibility will require further study.

In summary, these in vitro studies suggest that alterations in PI synthesis and PPI turnover induced by glucose in high AR2-expressing RPE cells occur in the absence of detectable shifts in cytoplasmic redox, and probably reflect sorbitol-induced MI depletion (29) rather than "metabolic pseudohypoxia" (9). Extrapolation of these observations to other cell culture or in vivo systems should be undertaken only with great caution given the wide differences in the metabolic characteristics of various experimental models. However, the emerging relationship between pyruvate metabolism and Na-MI cotransport may constitute a novel pathogenetic link between hyperglycemia, ischemia, and MI depletion in complications-prone diabetic tissues. These studies thus provide a theoretical alternative interpretation for the reported salutary effects of pyruvate supplementation on diabetic vascular dysfunction, namely enhancement of MI uptake and correction of cellular MI depletion. These results also suggest that glucose-induced enhancement of de novo synthesis of DAG may be independent of the sorbitol pathway, as initially proposed (37). These results, and others implying acute AR2-mediated nerve ischemia in diabetes (34), should lead to reassessment of the role of putative derangement in $\mathrm{NADH} / \mathrm{NAD}^{+}$in the pathogenesis of diabetic neuropathy.

\section{Acknowledgments}

We thank Kevin Wass and Lisa Beyer for expert technical assistance and Sarah Lattimer-Greene for kind editorial advice and assistance.

The study was supported in part by the U.S. Public Health Service grant R01-DK38304 (D. A. Greene), the Michigan Diabetes Research and Training Center (P60-DK20572)(D. A. Greene), the Washington University Diabetes Research and Training Center (P60-DK20579), and the Washington University Mass Spectrometry Resource (RR00954).

\section{References}

1. Greene, D. A., S. Lattimer-Greene, and A. A. Sima. 1989. Pathogenesis of diabetic neuropathy: role of altered phosphoinositide metabolism. Crit. Rev. Neurobiol. 5:143-219.

2. Kinoshita, J. H. 1974. Mechanisms initiating cataract formation. Proctor Lecture. Invest. Ophthalmol. 13:713-724.

3. Bagnasco, S. M., S. Uchida, R. S. Balaban, P. F. Kador, and M. B. Burg. 1987. Induction of aldose reductase and sorbitol in renal inner medullary cells by elevated extracellular NaCl. Proc. Natl. Acad. Sci. USA. 84:1718-1720.

4. Burg, M. B., and P. F. Kador. 1988. Sorbitol, osmoregulation, and the complications of diabetes. J. Clin. Invest. 81:635-640.

5. Bagnasco, S. M., H. R. Murphy, J. J. Bedford, and M. B. Burg. 1988. Osmoregulation by slow changes in aldose reductase and rapid changes in sorbitol flux. Am. J. Physiol. 254:C788-C792.

6. Morrison, A. D., R. S. Clements, Jr., S. B. Travis, F. Oski, and A. I. Winegrad. 1970. Glucose utilization by the polyol pathway in human erythrocytes. Biochem. Biophys. Res. Commun. 40:199-205.

7. Carroll, P. B., B. M. Thornton, and D. A. Greene. 1986. Glutathione redox state is not the link between polyol pathway activity and myo-inositol-related $\mathrm{Na}^{+}-\mathrm{K}^{+}$-ATPase defect in experimental diabetic neuropathy. Diabetes. 35:1282-1285.

8. Pugliese, G., R. G. Tilton, and J. R. Williamson. 1991. Glucose-induced metabolic imbalances in the pathogenesis of diabetic vascular disease. Diabetes Metab. Rev. 7:35-59.

9. Williamson, J. R., K. Chang, M. Frangos, K. S. Hasan, Y. Ido, T. Kawamura, J. R. Nyengaard, M. van den Enden, C. Kilo, and R. G. Tilton. 1993 Hyperglycemic pseudohypoxia and diabetic complications. Diabetes. 42:801813.

10. Moriyama, T., A. Garcia-Perez, and M. B. Burg. 1990. Factors affecting the ratio of different organic osmolytes in renal medullary cells. Am. J. Physiol. 259:F847-F858.

11. Nakanishi, T., R. J. Turner, and M. B. Burg. 1990. Osmoregulation of betaine transport in mammalian renal medullary cells. Am. J. Physiol. 258:F1061-F1067.

12. Kwon, H. M., A. Yamauchi, S. Uchida, R. B. Robey, A. Garcia-Perez, M. B. Burg, and J. S. Handler. 1991. Renal Na-myo-inositol cotransporter mRNA expression in Xenopus oocytes: regulation by hypertonicity. Am. J. Physiol. 260:F258-F263.

13. Nakamura, J., M. A. Del Monte, D. Shewach, S. A. Lattimer, and D. A. Greene. 1992. Inhibition of phosphatidylinositol synthase by glucose in human retinal pigment epithelial cells. Am. J. Physiol. 262:E417-E426.

14. Thomas, T. P., E. L. Feldman, J. Nakamura, K. Kato, M. Lien, M. J. Stevens, and D. A. Greene. 1993. Ambient glucose and aldose reductase-induced myo-inositol depletion modulate basal and carbachol-stimulated inositol phospholipid metabolism and diacylglycerol accumulation in human retinal pigment epithelial cell culture. Proc. Natl. Acad. Sci. USA. 90:9712-9716.

15. Winegrad, A. I. 1987. Banting lecture 1986. Does a common mechanism induce the diverse complications of diabetes? Diabetes. 36:396-406.

16. Greene, D. A., S. A. Lattimer, and A. A. Sima. 1988. Are disturbances of sorbitol, phosphoinositide, and $\mathrm{Na}^{+}-\mathrm{K}^{+}$-ATPase regulation involved in pathogenesis of diabetic neuropathy? Diabetes. 37:688-693.

17. Henry, D. N., M. Del Monte, D. A. Greene, and P. D. Killen. 1993. Altered aldose reductase gene regulation in cultured human retinal pigment epithelial cells. J. Clin. Invest. 92:617-623.

18. Stevens, M. J., T. P. Thomas, P. D. Killen, and D. A. Greene. 1993. Aldose reductase gene expression and osmotic dysregulation in cultured human retinal pigment epithelial cells. Am. J. Physiol. 265:E428-E438.

19. Del Monte, M. A., R. Rabbani, T. C. Diaz, S. A. Lattimer, J. Nakamura, M. C. Brennan, and D. A. Greene. 1991. Sorbitol, myo-inositol, and rod outer 
segment phagocytosis in cultured hRPE cells exposed to glucose. In vitro mode of myo-inositol depletion hypothesis of diabetic complications. Diabetes. 40:1335-1345.

20. Del Monte, M. A., and I. H. Maumenee. 1980. New techniques for in vitro culture of human retinal pigment epithelium. Birth Defects Orig. Artic. Ser. 16:327-338.

21. Wiecko, J., and W. R. Sherman. 1979. Structures and mass specttral behavior of the inositol cyclic boronic esters. J. Am. Chem. Soc. 101:979-983.

22. Sherman, W. R., M. A. Stewart, and M. Zinbo. 1969. Mass spectrometric study on the mechanism of D-glucose 6-phosphate-L-myo-inositol 1-phosphate cyclase. J. Biol. Chem. 244:5703-5708.

23. Lowry, O. H., and J. V. Passonneau. 1972. A Flexible System of Enzymatic Analysis. Academic Press, Inc., Orlando, FL. 195 pp.

24. Preiss, J., C. R. Loomis, W. R. Bishop, R. Stein, J. E. Niedel, and R. M Bell. 1986. Quantitative measurement of sn-1,2-diacylglycerols present in platelets, hepatocytes, and ras- and sis-transformed normal rat kidney cells. J. Biol. Chem. 261:8597-8600.

25. Lee, C., S. K. Fisher, B. W. Agranoff, and A. K. Hajra. 1991. Quantitative analysis of molecular species of diacylglycerol and phosphatidate formed upon muscarinic receptor activation of human SK-N-SH neuroblastoma cells. J. Biol. Chem. 266:22837-22846.

26. Zhu, X., and J. Eichberg. 1990. 1,2-diacylglycerol content and its arachidonyl-containing molecular species are reduced in sciatic nerve from streptozotocin-induced diabetic rats. J. Neurochem. 55:1087-1090.

27. Zhu, X., and J. Eichberg. 1990. A myo-inositol pool utilized for phosphatidylinositol synthesis is depleted in sciatic nerve from rats with streptozotocin-induced diabetes. Proc. Natl. Acad. Sci. USA. 87:9818-9822.

28. Kawamura, T., S. Smith, and J. R. Williamson. 1990. Glucose-induced metabolic changes in tissue chamber granulation tissue. Diabetes. 39:192A (Abstr.)

29. Greene, D. A., A. A. Sima, M. J. Stevens, E. L. Feldman, and S. A.
Lattimer. 1992. Complications: neuropathy, pathogenetic considerations. Diabetes Care. 15:1902-1925.

30. Craven, P. A., C. M. Davidson, and F. R. DeRubertis. 1990. Increase in diacylglycerol mass in isolated glomeruli by glucose from de novo synthesis of glycerolipids. Diabetes. 39:667-674.

31. Pugliese, G., R. G. Tilton, A. Speedy, E. Santarelli, D. M. Eades, M. A. Province, C. Kilo, W. R. Sherman, and J. R. Williamson. 1990. Modulation of hemodynamic and vascular filtration changes in diabetic rats by dietary myo-inositol. Diabetes. 39:312-322.

32. Dickman, K. G., and L. J. Mandel. 1989. Glycolytic and oxidative metabolism in primary renal proximal tubule cultures. Am. J. Physiol. 257:C333-C340.

33. Travis, S. F., A. D. Morrison, R. S. Clements, Jr., A. I. Winegrad, and F. A Oski. 1971. Metabolic alterations in the human erythrocyte produced by increases in glucose concentration: the role of the polylol pathway. J. Clin. Invest. 50:2104-2112.

34. Cameron, N. E., M. A. Cotter, and P. A. Low. 1991. Nerve blood flow in early experimental diabetes in rats: relation to conduction deficits. Am. J. Physiol. 261:E1-E8.

35. Yasuda, H., M. Sonobe, M. Yamashita, M. Terada, I. Hatanaka, Z. Huitian, and Y. Shigeta. 1989. Effect of prostaglandin E1 analogue TFC 612 on diabetic neuropathy in streptozocin-induced diabetic rats. Comparison with aldose reductase inhibitor ONO 2235. Diabetes. 38:832-838.

36. Stevens, M. J., E. L. Feldman, J. Dananberg, M. Kamijo, P. D. Killen, S. A. Lattimer, A. A. Sima, and D. A. Greene. 1993. Nitric oxide deficiency mediates nerve conduction slowing in experimental diabetic neuropathy. Diabetologia. 36:A51. (Abstr.)

37. Lee, T. S., L. C. MacGregor, S. J. Fluharty, and G. L. King. 1989. Differential regulation of protein kinase $\mathrm{C}$ and $(\mathrm{Na}, \mathrm{K})$-adenosine triphosphatase activities by elevated glucose levels in retinal capillary endothelial cells. J. Clin. Invest. 83:90-94 [retracted by Lee T. S., L. C. MacGregor, S. J. Fluharty, and G. L. King J. Clin. Invest. 1992. 89(2):717]. 